Revista Universo Contábil, ISSN 1809-3337

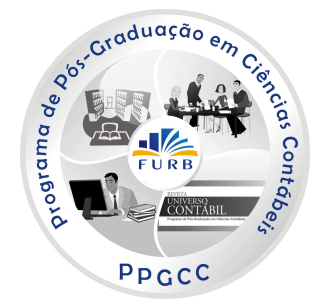

\title{
ADOÇÃO DE PRÁTICAS DE GESTÃO EXTERNA DE CUSTOS: UM ESTUDO MULTICASO EM EMPRESAS DA REGIÃO DA SERRA GAÚCHA ${ }^{1}$
}

\section{ADOPTION OF EXTERNAL COST MANAGEMENT PRACTICES: A MULTICASE STUDY ON COMPANIES OF SERRA GAÚCHA REGION}

\section{ADOPCIÓN DE PRÁCTICAS DE GESTIÓN DE COSTES EXTERNOS: UN ESTUDIO MULTICASO EN EMPRESAS DE LA REGIÓN DE LA SIERRA GAUCHA}

\author{
Marcos Antonio de Souza \\ Doutor em Controladoria e Contabilidade pela FEA/USP \\ Professor do Curso de Mestrado em Ciências Contábeis da Unisinos \\ Endereço: Av. Unisinos, 950, Sala 5A401a, Bairro Cristo Rei \\ CEP: 93022-000 - São Leopoldo/RS - Brasil \\ E-mail:marcosas@unisinos.br \\ Telefone: (51) 3554-2572 \\ Sabrina Trejes Marengo \\ Mestranda em Ciências Contábeis na Unisinos \\ Endereço: Av. Unisinos, 950, Sala 5A401a, Bairro Cristo Rei \\ CEP: 93022-000 - São Leopoldo/RS - Brasil \\ E-mail: sabrinamarengo@hotmail.com \\ Telefone: (51) 3554-2572 \\ Sinara Jaroseski \\ Mestranda em Ciências Contábeis na Unisinos \\ Endereço: Av. Unisinos, 950, Sala 5A401a, Bairro Cristo Rei \\ CEP: 93022-000 - São Leopoldo/RS - Brasil \\ E-mail: sinara_26@hotmail.com \\ Telefone: (51) 3554-2572
}

\section{RESUMO}

Com o aumento da competitividade entre as empresas, caracterizada por acirrada disputa de mercado, a busca por vantagem competitiva é uma necessidade contínua e crescente. As empresas passaram a ser entendidas e gerenciadas como parte de um sistema, participando de uma frequente troca de informações com o ambiente externo. Isso significa que somente a

\footnotetext{
Artigo recebido em 18.05.2011. Revisado por pares em 02.08.2011. Reformulado em 25.09.2011. Recomendado para publicação em 28.09.2011 por Ilse Maria Beuren (Editora). Publicado em 30.04.2012. Organização responsável pelo periódico: FURB.
} 
gestão interna já não é mais suficiente para competir. No que se refere aos custos, isso significa que além dos custos próprios também é necessário que a empresa monitore os custos de outras empresas, particularmente dos concorrentes. Neste contexto, o objetivo deste artigo é identificar a adoção de práticas de análise externa de custos em sete empresas da Região da Serra Gaúcha. Trata-se de uma pesquisa exploratória e qualitativa, organizada em forma de um estudo de caso múltiplo. A coleta de dados, realizada no período de novembro e dezembro/2010, foi conduzida por meio de entrevistas semi-estruturadas e análise de conteúdo. Os principais resultados indicam que algumas práticas da gestão externa de custos são utilizadas pelas empresas, porém de forma ainda incipiente. As práticas mais indicadas pelas empresas foram: engenharia reversa (3), markup reverso (1), sistema de informações (2) e análise da cadeia de valor (3). Portanto, o posicionamento das empresas é ainda muito distante do que apregoa a literatura sobre o tema. As dificuldades em acessar dados externos, a falta de pessoal especializado nessas atividades e a satisfação com as informações atuais são os principais argumentos para o baixo uso.

Palavras-chave: Gestão estratégica de custos. Análise externa de custos. Vantagem competitiva.

\section{ABSTRACT}

With the increase of competitiveness among companies, characterized by strong market dispute, the search for competitive advantage is a continuing and growing necessity. The companies came to be understood and managed as part of a system, participating in a frequent information exchange with the external environment. This means that only the internal management is no longer enough to compete. With regard to costs, this means that besides the own costs is also necessary that the company monitor the costs of other companies, particularly competitors. In this context, the goal of this article is to identify the adoption of external cost analysis practices by seven companies located in Serra Gaúcha region. This is an exploratory and qualitative study, organized in a multiple case study format. Data collection, carried out in the period of November and December/2010 was conducted through semi-structured interviews and content analysis. The main results indicate that some of the external cost management practices are used by companies, yet in an incipient form. The practices most listed by companies were: reverse engineering (3), reverse markup (1), information system (2), value chain analysis (3). Therefore, the positioning of the companies is still far from that emphasized by literature on the subject. Difficulties in accessing external data, lack of personnel skilled in these activities and satisfaction with current information are the main arguments for the low usage.

Keywords: Strategic cost management. External cost analysis. Competitive advantage.

\section{RESUMEN}

Con una mayor competitividad entre las empresas, que se caracteriza por una fuerte competencia en el mercado, la búsqueda por ventaja competitiva es una necesidad constante y creciente. Las empresas pasaron a ser entendidas y manejadas como parte de un sistema, participando en un intercambio frecuente de información con el ambiente externo. Eso significa que sólo la gestión interna ya no es suficiente para competir. Respecto a los costes, ello significa que además de los propios costes, la empresa debe controlar los costes de otras empresas, en especial de los competidores. En este contexto, el objetivo de este trabajo es identificar la adopción de métodos de análisis de costes externos por siete empresas de la región de la Sierra Gaucha. Tratase de un estudio exploratorio, descriptivo y cualitativo, 
organizado como un estudio multicaso. Los datos fueron recolectados en los meses de noviembre y diciembre de 2010, a través de entrevistas semi-estructuradas y análisis de contenido. Los principales resultados indican que algunas prácticas de los costes de gestión externa son utilizadas por las empresas, pero en un nivel aún incipiente. Las prácticas más utilizadas por las empresas son: ingeniería inversa (3), markup inverso (1), sistema de información (2) y análisis de la cadena de valor (3). Por lo tanto, el posicionamiento de las empresas aún está lejos de lo que trata la literatura sobre el tema. Las dificultades de acceso a datos externos, la falta de personal especializado en estas actividades y la satisfacción con la información actual son los principales argumentos para el escaso uso.

Palabras-clave: Gestión estratégica de costes. Análisis externo de costes. Ventaja competitiva.

\section{INTRODUÇÃO}

O ambiente em que as empresas estão inseridas encontra-se em permanente transformação. É uma consequência da globalização dos mercados, caracterizada pela acirrada concorrência e avanços tecnológicos, impulsionando as empresas a um grau maior de flexibilidade para sobreviver nesse contexto de alta competitividade (WERNKE, 2008).

Conquistar e manter a competitividade são desafios impostos às organizações, com a informação passando a ter mais relevância para decisões. A Gestão Estratégica de Custos (GEC) é um dos instrumentos que colaboram para o alcance dessa competitividade, cujas práticas surgiram em resposta às críticas sobre a utilidade das informações de custos até então adotadas pela contabilidade gerencial (JOHNSON; KAPLAN, 1987; MONDEN, 1995).

A importância da GEC na competitividade surge porque ela permite analisar não apenas os processos em que há agregação de valor por parte da empresa, mas a cadeia de valor como um todo. Para Martins (2003), a GEC requer uma análise mais profunda dos custos que estão além dos limites da empresa. É nesse contexto que está inserida a análise externa de custos, a qual contempla os custos na cadeia de suprimentos, e também os da cadeia de distribuição, possibilitando redução de custos não só para a empresa, mas também para os diferentes elos da cadeia.

Aguiar, Rezende e Rocha (2008) abordam que a obtenção da vantagem competitiva decorre da capacidade da empresa em criar valor em nível superior à concorrência. Para os autores isso exige tanto melhorias nos processos internos como aperfeiçoamento nos relacionamentos com os membros que integram a cadeia de valor da qual ela faz parte. Além do âmbito dessa cadeia de valor, com presença mais marcante de fornecedores e clientes, a análise externa também considera conhecer a estrutura dos custos dos concorrentes (COOPER; SLAGMULDER, 1998).

Tem-se então que a análise externa de custos surgiu da necessidade de a empresa olhar para fora, olhar para a sua cadeia de valor, descobrir seus parceiros de negócios, conhecer sua rede de cooperação, analisar seus concorrentes. Há aqui o reconhecimento de que, isoladamente, a gestão interna de custos não mais é suficiente para o alcance da eficiência global e consequente vantagem competitiva.

Neste contexto, esse estudo tem como objetivo identificar a adoção de práticas de análise externa de custos por empresas da região da Serra Gaúcha. A relevância do estudo está em tratar da gestão de custos, considerada pela literatura como relevante na conquista e manutenção da competitividade pelas empresas. Essa relevância tem sido reconhecida pela literatura, dadas as condições de um mercado altamente competitivo e limitador a que ineficiências internas sejam repassadas aos clientes via preço de venda. Estudos como os desenvolvidos por Porter (1992), Cooper e Slagmulder (1998), Guilding (1999), Miranda 
(2002), Cooper e Slagmulder (2004), Heinen (2005), Casella (2008), Aguiar, Rezende e Rocha (2008), Agndal e Nilsson (2010), reafirmam tal relevância.

A contribuição do estudo está em oportunizar a discussão dessa prática de GEC, além de gerar informações passíveis de comparação com outras pesquisas e com o conteúdo teórico mais presente na atual literatura de custos. Esta é uma forma de verificar a adesão e validação que as empresas atribuem às teorias desenvolvidas sobre o tema, possibilitando o aperfeiçoamento de ambos, teoria e prática.

\section{REVISÃO DE LITERATURA}

\subsection{Gestão Estratégica de Custos (GEC)}

Conforme argumentos apresentados por Johnson e Kaplan (1987), a GEC teve sua origem na perda da competitividade das empresas americanas e na crítica de autores da área contábil, especialmente dos EUA, à visão tradicional da contabilidade de custos. Ela seria disfuncional à gestão empresarial num ambiente de economia globalizada, que exige como atributos fundamentais a obtenção de vantagens competitivas apoiadas nas inovações tecnológicas, no desenvolvimento de articulações entre empresas (BACIC, 1994). Tem sido reconhecido que o trabalho de Simmonds (1981) foi um marco da literatura sobre essa visão estratégica na gestão de custos, derivada da definição de contabilidade gerencial estratégica dada pelo autor.

Para Shank e Govindarajan (1997, p. 4), a GEC é "uma análise de custos vista sob um contexto mais amplo, em que os elementos estratégicos tornam-se mais conscientes, explícitos e formais". Assim, para os autores os dados de custos são úteis no desenvolvimento de estratégias superiores, visando alcançar uma vantagem competitiva mais sustentável. Esse entendimento de Shank e Govindarajan (1997) corrobora o desenvolvimento teórico inicial de Simmonds (1981, p. 26), para o qual "a contabilidade gerencial estratégica pode ser definida como a provisão e análise de dados da contabilidade gerencial sobre os negócios e seus competidores para uso no desenvolvimento e monitoramento das estratégias de negócio".

Sob o aspecto da amplitude da GEC, Quesado e Rodrigues (2007) argumentam que ela extrapola o ambiente interno da empresa, abrangendo todo o sistema que a envolve, analisando-o para uma melhor compreensão da estratégia e dos elementos que interferem na composição da cadeia de valor. Para Leite (2000), a GEC visa a redução de custos e a melhoria da posição competitiva, isso porque ela assume uma postura diferente em relação à gestão tradicional de custos, conforme apresentado no Quadro 1.

\begin{tabular}{|l|l|}
\hline \multicolumn{1}{|c|}{ Gestão Tradicional de Custos } & \multicolumn{1}{c|}{ Gestão Estratégica de Custos } \\
\hline Perspectiva ex-post & Perspectiva ex-ante \\
\hline Controle corretivo & Controle preventivo \\
\hline Suporte a gestão corrente & Suporte a gestão estratégica \\
\hline Inter-relações no processo interno & Inter-relações na cadeia de valor \\
\hline Informação fiável & Informação pertinente (relevância) \\
\hline Ênfase nos custos (redução de custos) & Ênfase na criação de valor (posição competitiva) \\
\hline
\end{tabular}

Quadro 1 - Gestão tradicional versus a gestão estratégica de custos

Fonte: Leite (2000).

O conteúdo do Quadro 1 mostra que a gestão estratégica de custos trabalha preventivamente e num contexto mais amplo, procurando não só atingir a redução dos custos mas também em como conquistar e manter a vantagem competitiva. Mais diretamente relacionado ao foco desta pesquisa, tem-se que enquanto a gestão tradicional focaliza as interrelações do processo interno, a gestão estratégica focaliza também o ambiente externo ao tratar das inter-relações na cadeia de valor e dos custos dos concorrentes. Isso a conduz à gestão externa de custos. 


\subsection{Análise Externa de Custos}

De acordo com Oliva, Sobral e Teixeira (2006), a organização é entendida como um sistema aberto composto de diferentes partes relacionadas, que operam com objetivos comuns, tais como a busca da vantagem competitiva e a criação de valor ao acionista. Este sistema é caracterizado pelas partes da organização e pelas inter-relações existentes entre elas.

As constantes mudanças no ambiente externo têm ocasionado grandes efeitos sobre as organizações, impondo a elas que tenham capacidade de adaptação às condições externas. Coase (1991, p. 115) explica que "os custos de transação são os custos de coletar informações, os custos de negociações e os de estabelecimento de contratos". Esses custos refletem a amplitude de consideração a ser feita em relação à análise externa de custos.

Sob a óptica de Flores et al. (2010), as empresas tendem a ter dificuldade na sua gestão de custos quando atuam isoladas no mercado. Os autores mencionam que essa dificuldade das empresas solitárias pode ser superada pela iniciativa da análise conjunta de informações de custos, materializada pelo desenvolvimento de parcerias e práticas de análise externa no contexto da cadeia de valor.

Considerando, de acordo com Aguiar, Rezende e Rocha (2008), que a obtenção da vantagem competitiva também requer uma análise dos custos que não são gerados dentro da empresa, constata-se que somente aplicar práticas de gestão de custos internamente não bastaria para a total aplicação da gestão de custos. Integram essa visão os conceitos da gestão interorganizacional de custos. Assim, apoiadas na análise dos custos dos concorrentes e na gestão interorganizacional de custos, as práticas de gestão externa de custos aplicáveis à rede de relacionamentos da empresa são apresentados nas seções seguintes.

\subsection{Análise dos Custos dos Concorrentes}

A busca das empresas pela vantagem competitiva já faz parte do senso comum e está amplamente discutida pela literatura. Hamel e Prahalad (1995), Shank e Govindarajan (1997), Porter (2004), são alguns autores que tratam desses aspectos. Diante desse entendimento, analisar o comportamento do concorrente é uma ação importante para que as empresas ganhem vantagem competitiva.

Casella (2008, p. 22) entende que a análise dos custos dos concorrentes "envolve a análise do posicionamento estratégico da empresa comparada aos seus concorrentes, utilizando-se da GEC e da Inteligência Competitiva (IC)". Entre os aspectos do comportamento do concorrente há destaque para as informações de custo, dada sua relevância na formação do preço de venda, do lucro e da manutenção da fatia de mercado em disputa.

No contexto da análise dos custos dos concorrentes, Gordon (2004) define a IC como o processo para obtenção e análise de informações publicamente disponíveis, que possam contribuir para a consecução dos objetivos competitivos de uma empresa. Para o autor essas informações possibilitam alcançar os objetivos estabelecidos via facilitação de outros processos como a aprendizagem e aperfeiçoamento organizacional, a criação de diferenciação e a administração da concorrência. Ainda, de acordo com Deschamps e Nayak (1995), a IC permite avaliar a evolução da estratégia competitiva ao longo do tempo por meio de mudanças na estrutura de concorrentes, de produtos substitutos e novos entrantes.

A análise dos custos dos concorrentes é uma das principais práticas da análise externa de custos e envolve o emprego de diversas técnicas para obter a importante informação sobre os custos praticados pela concorrência. A finalidade principal é ter um custo aproximado com o qual a empresa pode formular e implantar suas estratégias de ação, tais como ofertar maior valor ao cliente com custos reduzidos e potencializando a lucratividade. As principais técnicas empregadas nessa análise estão apresentadas no Quadro 2. 


\begin{tabular}{|c|l|}
\hline Técnicas & \multicolumn{1}{|c|}{ Definição } \\
\hline \multirow{3}{*}{ Benchmarking } & $\begin{array}{l}\text { Envolve identificação das melhores práticas de mercado as quais conduzem a um } \\
\text { desempenho superior. Objetiva aplicar um foco externo nas atividades internas, funções e } \\
\text { operações, a fim de atingir uma melhoria contínua (MCNAIR; LEIBFRIED, 1992 apud } \\
\text { CINQUINI; TENUCCI, 2007). }\end{array}$ \\
\hline Engenharia & $\begin{array}{l}\text { Permite decompor os produtos dos concorrentes em múltiplas partes e analisá-las, } \\
\text { observando materiais, componentes, métodos e processos funcionais (HEINEN; HOFFJAN, } \\
\text { Reversa } \\
\text { 2005). A engenharia reversa auxilia na identificação dos custos e possíveis melhorias de } \\
\text { processos (BARTZ; STAUDT; SOUZA, 2005). }\end{array}$ \\
\hline $\begin{array}{c}\text { Estudos como os de Moon e Bates (1993), Guilding (1999) e Casella (2008), se referem a } \\
\text { Reversa }\end{array}$ & $\begin{array}{l}\text { publicadas". Guilding (1999) ressalta que além da análise de custos o uso dessa técnica } \\
\text { permite acompanhar volume e valor de vendas e níveis de lucros, bem como movimentação } \\
\text { de ativos e passivos. }\end{array}$ \\
\hline $\begin{array}{l}\text { Utiliza do preço de venda de um produto concorrente para chegar ao seu custo. Alguns } \\
\text { componentes do preço são identificáveis (tributos, matéria-prima e processo de produção). } \\
\text { Reverso }\end{array}$ & $\begin{array}{l}\text { Enquanto alguns itens como margem e custos fixos não são fáceis de identificar, } \\
\text { informações obtidas pela Engenharia e Contabilidade. Reversas podem chegar a um valor } \\
\text { estimado do custo do concorrente (FLORES et al., 2010). }\end{array}$ \\
\hline
\end{tabular}

Quadro 2 - Práticas de análise de custos dos concorrentes

Fonte: Elaboração própria.

Como destacado anteriormente nesta seção, diversas são as formas e fontes de se obter informações sobre os concorrentes (CASELLA, 2008). De outra parte, e dentro da delimitação que as pesquisas científicas envolvem em sua elaboração, algumas outras práticas de se obter informações dos concorrentes, além das citadas no Quadro 2, não são aqui consideradas. Isso se aplica, por exemplo, à contratação de empregado do concorrente detentor de dados confidenciais de qualquer natureza, conforme abordado por Moreira (1999).

\subsection{Análise de Custos da Cadeia de Valor}

Cadeia de Valor, segundo Borinelli e Rocha (2007, p. 149), "é uma seqüência de atividades que se inicia com a origem dos recursos e vai até o descarte do produto pelo último consumidor". De acordo com Machado e Souza (2006), é arriscado ignorar as ligações da cadeia de valor, pois ganhar e sustentar vantagem competitiva requer que uma empresa compreenda todo o sistema, e não apenas parte da cadeia de que participa.

A análise de custos da cadeia de valor é uma prática da análise externa de custos. Seu objetivo é analisar os custos dos diversos tipos de elos ou relações da cadeia. Porter (1992) afirma que o ponto de partida para a análise de custos é definir a cadeia de valores de uma empresa e atribuir custos operacionais e ativos àquelas atividades de valor que a compõem.

Perez, Oliveira e Costa (1999) entendem por cadeia de valor o conjunto de atividades criadoras de valor, desde a fonte de suprimentos de matérias-primas, até o produto final entregue aos clientes. Miranda (2002) complementa que para uma análise produtiva é necessário que as atividades das empresas que compõem a cadeia sejam organizadas de forma eficiente e competitiva em relação às cadeias que competem pelo mesmo consumidor final.

A compreensão da utilidade da análise da cadeia de valor, e da extensão externa da sua aplicação está expressamente apresentada no estudo de Cokins (2001), quando afirma que o gerenciamento da cadeia de valor força as organizações a entenderem as relações e os custos inter-firmas (relações com clientes e/ou fornecedores), superando, assim, as restrições provocadas pela concentração unicamente na gestão dos custos internos. Pil e Holweg (2006) destacam a utilidade da análise da cadeia de valor como instrumento de indução ao desenvolvimento, em conjunto com fornecedores e clientes, das oportunidades de inovações. 


\subsection{Gestão Interorganizacional de Custos (GIC)}

A GIC, de acordo com Cooper e Slagmulder (1998), surgiu no campo da contabilidade gerencial como um termo de propósito geral, referente à utilização específica de práticas de gestão estratégica orientadas para a redução de custos em conjunto pelos parceiros.

Ainda conforme Cooper e Slagmulder, (1998), as práticas da GIC facilitam a coordenação de redução de custos nas empresas de duas formas: a) ajuda a identificar maneiras de fazer a interface entre as empresas mais eficientes; b) ajuda a empresa e os seus compradores e fornecedores a encontrar outras maneiras de reduzir os custos dos produtos.

Observa-se, então, que a GIC tem como objetivo encontrar soluções através de ações coordenadas e cooperativas entre as organizações da cadeia, o que não seria possível se as empresas tentassem reduzir os custos agindo isoladamente (SOUZA; ROCHA, 2008).

Cooper e Slagmulder (1999) destacam que para aplicação da GIC é necessário um relacionamento propício, que envolva aspectos de interdependência, estabilidade, cooperação, benefícios mútuos e confiança; quanto mais intenso o nível de relacionamento, mais propícia é a aplicação da GIC. Souza (2008) observa que a probabilidade de operacionalização da GIC com sucesso depende de cinco variáveis, apresentadas no Quadro 3.

\begin{tabular}{|l|l|}
\hline \multicolumn{1}{|c|}{ Fatores } & \multicolumn{1}{c|}{ Características } \\
\hline Produtos & 1) Margem \\
& 2) Funcionalidade \\
\hline Componentes & 1) Restrição Tecnológica \\
& 2) Índice de Valor \\
\hline \multirow{2}{*}{$\begin{array}{l}\text { Nível de Relacionamento com os } \\
\text { Fornecedores e Parceiros }\end{array}$} & 1) Comum \\
& 2) Auxiliar \\
\hline \multirow{3}{*}{ Tipo de Cadeia } & 3) Principal \\
& 4) Familiar \\
\hline Mecanismos & 1) Tirania \\
& 2) Oligarquia \\
\hline
\end{tabular}

Quadro 3 - Variáveis para aplicação da GIC

Fonte: Souza (2008).

O Quadro 3 apresenta as características que devem ser consideradas em relação a cada fator condicionante da GIC. Tais fatores são caracterizados conforme Souza (2008) como:

a) Produtos - grande etapa para implantação da GIC. Deve ser analisado cada tipo de produto ou serviço, da carteira atual ou que se queira lançar;

b) Componentes - o produto é composto por componentes. A empresa não precisa aplicar a GIC para um produto como um todo. A análise de componentes é uma importante etapa, pois, pode-se optar em realizar a GIC somente para alguns desses componentes;

c) Nível de Relacionamento - o objetivo fundamental é discutir sobre as características adequadas dos relacionamentos base para a aplicação da GIC e, com base nesses aspectos, criar uma tipologia dos relacionamentos, identificando-se os favoráveis à aplicação da GIC;

d) Tipo de Cadeia - o objetivo é discutir as características de cada tipo de cadeia e identificar qual ou quais são favoráveis à aplicação da GIC;

e) Mecanismos - são artefatos, aparelhos e instrumentos que auxiliam na gestão de custos com o objetivo de orientar, controlar, medir, informar, dar parâmetros, ser guia para organizações, tornando possível a aplicação da GIC.

Essas variáveis para aplicação da GIC revelam-se como mecanismos que possibilitam o alcance dos benefícios da GIC. E esses benefícios ocorrem, na interpretação de Agndal e 
Nilsson (2008), porque a GIC revela-se como esforços coordenados de compradores e fornecedores para redução de custos, referendando a afirmativa anterior de Cooper e Slagmulder (2003) de que a gestão interorganizacional de custos é uma ação disciplinada para a gestão de custos por meio de ações cooperadas de empresas em uma cadeia de suprimentos.

A Open-Book Accounting (OBA) é uma prática da Gestão Interorganizacional de Custos. Consiste na abertura das informações de custos entre empresas a fim de, juntamente com seus fornecedores e clientes, reduzir custos e incrementar resultados (FLORES et al. 2010). Esse intercâmbio de informações requer um nível de confiança associado a uma relação de longo prazo.

A troca de informações, no entanto, expõe membros da cadeia de abastecimento para o risco de comportamento oportunista. Tal situação tende a ser agravada pelo fato de que, na prática, compartilhar informações tende a ser unidirecional, por parte do fornecedor ao comprador. Diante dessa situação, são estabelecidas condições para a troca de informações, as quais determinam que tipo de dados os fornecedores estejam dispostos a compartilhar (AGNDAL; NILSSON, 2010).

O estudo de Aguiar, Rezende e Rocha (2008) aborda as redes de cooperação. Afirmam que a troca de informações inicia-se pela definição dos demonstrativos elaborados pela empresa líder da rede de cooperação, nos quais ela formaliza os elementos de custos evidenciados em cada elo da rede; eles devem fornecer informações referentes aos seus principais elementos de custos. Na sequência fixa-se o custo-meta para os fornecedores.

O open-book accounting, de acordo com Kajuter e Kulmala (2005), caracteriza-se com dois significados: a) melhoria da eficiência dos custos da cadeia de valor; b) ferramenta para construção de confiança nos relacionamentos entre cliente e fornecedor. Kajuter e Kulmala acrescentam que há pouca evidência empírica de como fazer os trabalhos do OBA e como evitar potenciais armadilhas.

Agndal e Nilsson (2010) realizaram um estudo multicasos com três empresas suíças de diversos segmentos e analisaram as práticas do OBA frente as estratégias de compras. Os dados foram coletados por meio de entrevistas semi-estruturadas com compradores e fornecedores das empresas. Os resultados indicam que nas relações entre compradores e vendedores os dados de custos servem essencialmente para reduzir preço de compra.

Nesse mesmo estudo foi também verificado que incentivos estabelecidos com base nos resultados tangíveis de curto prazo são dados aos fornecedores para que abram suas informações. Assim, em um acordo de troca que beneficie a ambos, comprador e fornecedor, constatou-se que a divulgação de dados pode oferecer suporte a redução de custos.

\section{ASPECTOS METODOLÓGICOS}

\subsection{Classificação Metodológica da Pesquisa}

Dado o objetivo de investigar a adoção das práticas de análise externa de custos por empresas da Serra Gaúcha, esta pesquisa é de natureza exploratória. Segundo Gil (1999), a pesquisa exploratória é desenvolvida com o objetivo de proporcionar maior familiaridade com um objeto de estudo que tem sido pouco explorado.

Quanto à abordagem, a pesquisa se classifica como qualitativa. Conforme abordado por Oliveira (1998), a pesquisa qualitativa mostra-se adequada quando o pesquisador necessita de uma melhor compreensão sobre comportamentos de múltiplos fatores e elementos que implicam sobre determinados fatos.

A pesquisa foi desenvolvida por meio de um estudo de caso múltiplo. Yin (2005) observa que esses estudos podem ocorrer de forma única ou múltipla o que, na realidade, são duas variantes dos projetos de estudo de caso. A escolha dessa metodologia se deu em função dela possibilitar a consideração de um maior número de variáveis e da flexibilidade para 
coleta e análise de dados. Conforme Yin (2005), o estudo de caso é conduzido em grande detalhe, e baseia-se no uso de diversas fontes, inclusive da entrevista em profundidade.

Como forma de manter o rigor da pesquisa científica, foi realizado um protocolo de estudo de caso, conforme indicado por Yin (2005).

O roteiro da entrevista é formado de dois blocos de perguntas. No primeiro consta a identificação da empresa e do entrevistado (razão social da empresa, nome e formação do entrevistado, cargo, tempo de atuação na empresa, número de empregados, número de unidades e participação de mercado, local de atuação). O segundo bloco de perguntas compreende as práticas de análise externa de custos (benchmarking, engenharia reversa, contabilidade reversa, mark-up reverso, sistema de informações sobre concorrentes, gestão interorganizacional de custos, cadeia de valor e open book accounting).

\subsection{Procedimentos de Coleta e Análise dos Dados}

A coleta de dados foi realizada no período de novembro e dezembro/2010, desenvolvida através de entrevistas em profundidade, realizadas com os responsáveis pelas áreas de custos, contabilidade, engenharia e marketing. Utilizou-se um roteiro com perguntas abertas semi-estruturadas, a fim de permitir flexibilidade nas respostas. As entrevistas foram gravadas, facilitando assim a posterior análise das respostas dos respondentes.

De acordo com Lakatos e Marconi (1999), este tipo de entrevista é uma técnica em que o entrevistador segue um roteiro previamente estabelecido; havendo necessidade, durante o desenvolvimento da entrevista há liberdade de incluir questões para atingir o objetivo.

O propósito de formular tais questões é permitir ao pesquisador entender e capturar a perspectiva dos respondentes, por isso as questões não apresentam alternativas para respostas (ROESCH, 2009). O roteiro de questões foi submetido a um processo de pré-teste, aplicado em uma empresa que não integra a amostra da pesquisa. Após obter as respostas do pré-teste fez-se as alterações sugeridas, tais como mudanças de redação, maior objetividade em algumas questões e sugestão de inclusão de outras três mais diretamente relacionadas ao tema de pesquisa. Além das entrevistas, fez-se uso também da análise de conteúdo, uma forma de coleta de dados qualitativos. Como fontes secundárias, foram utilizados folders e relatórios disponibilizados pelas empresas, publicações em mídia escrita e eletrônica.

Foram selecionadas para o estudo empresas localizadas na Serra Gaúcha, cadastradas no Sindicato das Indústrias Metalúrgicas e de Material Elétrico de Caxias do Sul (SIMECS). O universo da pesquisa é composto por 20 empresas de setores distintos e com expressivo nível de faturamento, de acordo com as demonstrações contábeis submetidas ao SIMECS (2009). Para compor a amostra, foi enviado email a esse grupo de 20 empresas, solicitando a participação, com sete delas respondendo positivamente. Por solicitação das empresas elas não estão identificadas nominalmente, tratadas apenas por denominações fictícias.

Após realizar as entrevistas com os respondentes das empresas selecionadas, transcrevê-las e obter aprovações dos participantes, realizou-se a análise e interpretação do significado dos seus conteúdos. Os resultados estão apresentados na sequência.

Para realização da análise e interpretação dos dados coletados, foi definido um ponto de corte a partir do qual a empresa pesquisada é considerada usuária ou não das práticas de análise externa de custos. Este ponto de corte foi definido através de critérios de utilização classificados em quatro níveis de atendimento: utiliza muito raramente, utiliza parcialmente, utiliza totalmente, e não utiliza as práticas pesquisadas de análise externa de custos.

a) Critério - utilização de pelo menos uma das práticas pesquisadas de análise externa de custos; Classificação em nível de atendimento - utiliza muito raramente;

b) Critério - utilização de duas ou mais práticas pesquisadas de análise externa de custos; Classificação em nível de atendimento - utiliza parcialmente;

c) Critério - utilização de todas as práticas pesquisadas de análise externa de custos; 
Classificação em nível de atendimento - utiliza totalmente;

d) Critério - não utiliza nenhuma das práticas pesquisadas de análise de custos; Classificação em nível de atendimento - não utiliza.

\section{APRESENTAÇÃO E ANÁLISE DOS DADOS}

\subsection{Caracterização das Empresas e dos Entrevistados}

A pesquisa pautou-se na participação de sete empresas e nos respectivos respondentes. As caracterizações gerais desses participantes acham-se apresentadas no Quadro 4.

\begin{tabular}{|c|c|c|c|c|c|}
\hline Empresa & Faturamento & $\begin{array}{c}\text { Tempo e Ramo } \\
\text { de Atuação }\end{array}$ & Funcionários & Exportação & $\begin{array}{l}\text { Características } \\
\text { do Respondente }\end{array}$ \\
\hline Argentina & $\begin{array}{l}\text { R } \$ 700 \text { milhões. } \\
\text { Empresa de } \\
\text { grande porte } \\
\text { conforme } \\
\text { BNDES (2010). }\end{array}$ & $\begin{array}{l}30 \text { anos. } \\
\text { Equipamentos } \\
\text { petrolíferos e } \\
\text { conjuntos } \\
\text { automotivos. }\end{array}$ & $\begin{array}{l}3.000 \\
\text { funcionários } \\
\text { distribuídos } \\
\text { em } 22 \\
\text { unidades }\end{array}$ & $\begin{array}{l}\text { Representa de } \\
15 \% \text { a } 20 \% \text { das } \\
\text { vendas, } \\
\text { basicamente } \\
\text { Europa }\end{array}$ & $\begin{array}{l}\text { Gerente de } \\
\text { Controladoria; } \\
\text { cursou Ciências } \\
\text { Contábeis; Há } \\
15 \text { anos na } \\
\text { empresa. }\end{array}$ \\
\hline Brasil & $\begin{array}{l}\text { R\$ } 300 \text { milhões. } \\
\text { Empresa de } \\
\text { grande porte } \\
\text { conforme } \\
\text { BNDES (2010.) }\end{array}$ & $\begin{array}{l}10 \text { anos. } \\
\text { Fabricação de } \\
\text { carrocerias e } \\
\text { componentes } \\
\text { para ônibus }\end{array}$ & $\begin{array}{l}1.800 \\
\text { funcionários }\end{array}$ & $\begin{array}{l}20 \% \text { do } \\
\text { faturamento em } \\
2009 \text { e } 2 \% \text { em } \\
2010 .\end{array}$ & $\begin{array}{l}\text { Coordenador } \\
\text { Contábil; cursou } \\
\text { Ciências } \\
\text { Contábeis; Há } 6 \\
\text { anos na empresa. }\end{array}$ \\
\hline Chile & $\begin{array}{l}\text { Entre R \$ } 90 \\
\text { milhões e R\$ } 300 \\
\text { milhões. Empresa } \\
\text { Média - grande } \\
\text { BNDES (2010). }\end{array}$ & $\begin{array}{l}60 \text { anos. } \\
\text { Fabricação de } \\
\text { produtos } \\
\text { eletroeletrônicos }\end{array}$ & $\begin{array}{l}800 \\
\text { funcionários. }\end{array}$ & $\begin{array}{l}5 \% \text { do } \\
\text { faturamento }\end{array}$ & $\begin{array}{l}\text { Gerente de } \\
\text { Engenharia; } \\
\text { cursou } \\
\text { Engenharia } \\
\text { Elétrica. Há } 11 \\
\text { anos na empresa. }\end{array}$ \\
\hline Dinamarca & $\begin{array}{l}\text { R\$ } 800 \text { milhões } \\
\text { para } 2010 . \\
\text { Empresa de } \\
\text { grande porte } \\
\text { conforme } \\
\text { BNDES (2010). }\end{array}$ & $\begin{array}{l}45 \text { anos. } \\
\text { Produção de } \\
\text { implementos } \\
\text { agrícolas e } \\
\text { componentes } \\
\text { automotivos }\end{array}$ & $\begin{array}{l}1.600 \\
\text { funcionários. }\end{array}$ & $\begin{array}{l}12 \% \text { do } \\
\text { faturamento. }\end{array}$ & $\begin{array}{l}\text { Coordenador de } \\
\text { Planejamento } \\
\text { Econômico; } \\
\text { cursou Ciências } \\
\text { Contábeis; Há } 3 \\
\text { anos na empresa. }\end{array}$ \\
\hline Espanha & $\begin{array}{l}\text { R\$ } 370 \text { milhões } \\
\text { para } 2010 . \\
\text { Empresa de } \\
\text { grande porte } \\
\text { conforme } \\
\text { BNDES (2010). }\end{array}$ & $\begin{array}{l}18 \text { anos. } \\
\text { Fundição, } \\
\text { metalurgia e } \\
\text { produção de } \\
\text { motores. }\end{array}$ & $\begin{array}{l}2.200 \\
\text { funcionários } \\
\text { distribuídos } \\
\text { em } 7 \text { plantas } \\
\text { fabris. }\end{array}$ & $\begin{array}{l}5 \% \text { do } \\
\text { faturamento com } \\
\text { maior } \\
\text { concentração na } \\
\text { América Latina. }\end{array}$ & $\begin{array}{l}\text { Coordenador de } \\
\text { Custos e } \\
\text { Planejamento } \\
\text { Estratégico; } \\
\text { cursou Ciências } \\
\text { Contábeis. Há } 3 \\
\text { anos na empresa. }\end{array}$ \\
\hline França & $\begin{array}{l}\text { R\$ } 120 \text { milhões } \\
\text { para } 2010 . \\
\text { Média grande } \\
\text { empresa } \\
\text { conforme } \\
\text { BNDES (2010). }\end{array}$ & $\begin{array}{l}30 \text { anos. } \\
\text { Produção de } \\
\text { eletroeletrônicos }\end{array}$ & $\begin{array}{l}2.000 \\
\text { funcionários } \\
\text { distribuídos } \\
\text { em } 4 \text { plantas } \\
\text { produtivas. }\end{array}$ & $\begin{array}{l}4 \% \text { do } \\
\text { faturamento; } \\
\text { exporta para mais } \\
\text { de } 20 \text { países; } \\
\text { maior } \\
\text { concentração na } \\
\text { América Latina. }\end{array}$ & $\begin{array}{l}\text { Coordenador de } \\
\text { Estudos de } \\
\text { Marketing; } \\
\text { cursou } \\
\text { Administração } \\
\text { de Empresas. Há } \\
10 \text { anos na } \\
\text { empresa. }\end{array}$ \\
\hline Holanda & $\begin{array}{l}\text { R\$ } 137 \text { milhões } \\
\text { para } 2010 . \\
\text { Média - grande } \\
\text { empresa } \\
\text { conforme } \\
\text { BNDES (2010). }\end{array}$ & $\begin{array}{l}15 \text { anos. } \\
\text { Produz } \\
\text { guindastes e } \\
\text { cilindros } \\
\text { hidráulicos }\end{array}$ & $\begin{array}{l}1.600 \\
\text { funcionários } \\
\text { no mundo. No } \\
\text { Brasil conta } \\
\text { com } 170 .\end{array}$ & $\begin{array}{l}20 \% \text { do } \\
\text { faturamento com } \\
\text { concentração na } \\
\text { América Latina. }\end{array}$ & $\begin{array}{l}\text { Coordenador de } \\
\text { Custos; cursou } \\
\text { Ciências } \\
\text { Contábeis; Há } 3 \\
\text { anos na empresa }\end{array}$ \\
\hline
\end{tabular}

Quadro 4 - Caracterização das empresas pesquisadas e dos respondentes

Fonte: Dados da pesquisa. 
Observa-se no Quadro 4, que as empresas que compõem a amostra se assemelham, com uma exceção, por possuírem mais de uma década de fundação, a maioria há mais de trinta anos. Outra característica comum é a atuação no mercado externo.

Embora as empresas da amostra atuem em segmentos distintos, elas possuem elevado faturamento, o que as classifica como empresas de grande e médio-grande portes de acordo com os parâmetros estabelecidos pelo BNDES (2010). Também é expressiva a quantidade de funcionários contratados.

Dos respondentes, observa-se que a maioria possui formação superior em Ciências Contábeis, com exceção de dois respondentes, um em Engenharia e outro em Administração de Empresas. Todos eles ocupam cargo de coordenação ou gerência e lidam com a gestão dos custos. Observa-se também que todos atuam há mais de três anos nas empresas.

\subsection{Questōes Referentes à Análise Externa de Custos}

\subsubsection{Empresa Argentina}

Trata-se de uma empresa de capital aberto, composta por 22 unidades localizadas no Brasil e em alguns outros países da América Latina. Possui liderança de mercado na maioria dos segmentos em que atua, principalmente na produção de válvulas para aplicação industrial e na produção de equipamentos para exploração de petróleo e gás. Baseado na entrevista em profundidade realizada com o gerente de controladoria tem-se no Quadro 5 as informações gerais sobre a aplicação de práticas relacionadas à gestão externa de custos.

\begin{tabular}{|c|c|}
\hline Práticas & Identificação de adoção da prática pela empresa \\
\hline Benchmarking & $\begin{array}{l}\text { Algumas informações são trocadas em feiras ou encontros com fornecedores e } \\
\text { empresas do mesmo setor, porém com pouca relevância para a gestão da empresa. }\end{array}$ \\
\hline Engenharia Reversa & Não utiliza esta prática. \\
\hline $\begin{array}{c}\text { Contabilidade } \\
\text { Reversa }\end{array}$ & $\begin{array}{l}\text { A empresa utiliza a prática como ferramenta auxiliar, sem caráter estratégico ou } \\
\text { decisório, em função da maioria de seus concorrentes não ter obrigatoriedade de } \\
\text { divulgação. }\end{array}$ \\
\hline Mark-up Reverso & Não utiliza esta prática. \\
\hline $\begin{array}{l}\text { Sistema de } \\
\text { Informações }\end{array}$ & $\begin{array}{l}\text { O custo do concorrente é analisado pela área comercial da empresa através de } \\
\text { informações dos clientes ou representantes. O cliente abre o preço do produto } \\
\text { concorrente ou o representante faz papel de cliente comprador na empresa concorrente. } \\
\text { A empresa também participa de associações e entidades, como o Sindipetro (Sindicato } \\
\text { de Petroleiros), nas quais busca informações sobre mercado e concorrente. }\end{array}$ \\
\hline GIC & $\begin{array}{l}\text { O respondente afirma que normalmente as vendas são guiadas por preço, porém, em } \\
\text { parcela significativa do faturamento do ramo petrolífero são priorizadas características } \\
\text { como qualidade e funcionalidade, ficando o preço em segundo plano. }\end{array}$ \\
\hline Cadeia de Valor & $\begin{array}{l}\text { Quanto à parceria com fornecedores, no sentido de racionalização de custos, não é uma } \\
\text { prática usual da empresa. Com relação às parcerias com clientes, essa sim é muito } \\
\text { utilizada; de uma forma geral os clientes fazem inspeções, sugestões e algumas vezes } \\
\text { participam financeiramente no desenvolvimento de novos produtos e na melhoria de } \\
\text { processos. }\end{array}$ \\
\hline OBA & $\begin{array}{l}\text { Pratica com alguns clientes, quando existe a necessidade de justificar reajuste de preço. } \\
\text { Normalmente os que mais exigem são empresas do ramo automotivo e as informações } \\
\text { englobam custos de matéria-prima e mão-de-obra. Parcerias e desenvolvimentos } \\
\text { conjuntos ocorrem apenas esporadicamente. }\end{array}$ \\
\hline
\end{tabular}

Quadro 5 - Práticas de análise externa de custos adotadas pela empresa Argentina Fonte: Dados da pesquisa.

Observa-se que a empresa não utiliza as práticas de análise externas de custos em sua plenitude. De acordo com o respondente, as práticas tratadas nesse estudo não são consideradas relevantes para a empresa. $\mathrm{O}$ sistema atual tem atendido as necessidades informacionais e, portanto, não há planos da empresa em intensificar o uso dessas práticas 
Cabe lembrar, ainda, que se trata de uma empresa de grande porte, e com atuação no mercado externo, características de uma empresa competitiva atuando com relevância em mercados de concorrência acirrada. Assim, há aqui uma adesão muito parcial das práticas de gestão externa de custos, contrariando, pelo menos em parte, a necessidade e utilidade apresentadas pela literatura da área conforme conteúdo do referencial teórico desse estudo.

\subsubsection{Empresa Brasil}

A empresa, atuante no setor automotivo, possui um parque fabril no estado do Rio Grande do Sul e unidades em São Bernardo do Campo (SP), Bahia e México. O Quadro 6 apresenta as informações coletadas na empresa a respeito das práticas abordadas neste estudo. Conforme apresentado no Quadro 4 o respondente é o Coordenador Contábil da empresa.

\begin{tabular}{|c|l|}
\hline Práticas & \multicolumn{1}{c|}{ Identificação da adoção da prática pela empresa } \\
\hline Benchmarking & Não utiliza essa prática. \\
\hline $\begin{array}{c}\text { Engenharia } \\
\text { Reversa }\end{array}$ & $\begin{array}{l}\text { De acordo com o respondente a empresa não faz uso da engenharia reversa; diz não dar } \\
\text { conta nem do seu próprio processo que dirá analisar o processo do concorrente }\end{array}$ \\
\hline $\begin{array}{c}\text { Contabilidade } \\
\text { Reversa }\end{array}$ & $\begin{array}{l}\text { Utiliza raramente as demonstrações publicadas pelos concorrentes, pois acredita que } \\
\text { algumas informações não são confiáveis, exceto quando há auditoria externa. Algumas } \\
\text { informações são buscadas nos sites das empresas, do SERASA e da CVM, mas não } \\
\text { chega a fazer uma análise que seja utilizada na estratégia da empresa. }\end{array}$ \\
\hline Mark-up Reverso & Não utiliza essa prática. \\
\hline $\begin{array}{c}\text { Sistema de } \\
\text { Informações }\end{array}$ & $\begin{array}{l}\text { Troca de informações em feiras, ou através de ex-funcionários da concorrência que } \\
\text { trabalham atualmente na empresa, no entanto, essas informações não tem tido grandes } \\
\text { retornos em termos de redução de custos, mas sim em novidades e novas tecnologias. }\end{array}$ \\
\hline GIC & Não utiliza essa prática. \\
\hline Cadeia de Valor & $\begin{array}{l}\text { De acordo com o respondente a empresa não faz nenhum tipo de análise da cadeia de } \\
\text { valor. }\end{array}$ \\
\hline OBA & Não utiliza essa prática. \\
\hline
\end{tabular}

Quadro 6 - Práticas de análise externa de custos adotadas pela empresa Brasil

Fonte: Dados da pesquisa.

O respondente informou que a empresa não analisa os custos dos concorrentes. Alega, como motivo principal, o fato de que a troca de informações de custos não funciona porque cada um quer proteger o seu mercado e o acesso a tais informações é muito dificultado.

Verifica-se pelas informações coletadas que o uso das práticas pela empresa Brasil é muito restrito, quase inexistente. De acordo com seu respondente, a empresa utiliza apenas algumas informações disponibilizadas em feiras ou através de ex-funcionários, no entanto, destacou que essas informações não auxiliam na redução de custos.

O entrevistado acrescentou que a empresa já tem um elevado volume de trabalho na gestão das suas próprias atividades, não dispondo de estrutura para executar essas práticas de gestão externa de custos.

\subsubsection{Empresa Chile}

A empresa atua na fabricação de produtos eletrônicos, possui duas unidades produtivas, uma no Rio Grande do Sul e outra em São Paulo, além de centros de distribuição espalhados pelo Brasil. No Quadro 7 são apresentadas as informações coletadas na empresa a respeito das práticas abordadas neste estudo. O respondente é Gerente de Engenharia.

A análise do custo do concorrente é feita por pessoa exclusivamente dedicada a fazer esse tipo de avaliação. Para tanto, conforme informou o entrevistado, são escolhidos os produtos e concorrentes que estão "incomodando". 


\begin{tabular}{|c|c|}
\hline Práticas & Identificação da adoção da prática pela empresa \\
\hline Benchmarking & Não utiliza essa prática. \\
\hline $\begin{array}{c}\text { Engenharia } \\
\text { Reversa }\end{array}$ & $\begin{array}{l}\text { A empresa adquire os produtos pré-determinados na avaliação para fazer a engenharia } \\
\text { reversa. Um relatório é elaborado informando as características do produto, a lista de } \\
\text { materiais utilizados para sua composição e o custo estimado na sua fabricação e juntam- } \\
\text { se fotos com características específicas do produto. Além disso, é feita ainda uma análise } \\
\text { do custo do concorrente versus a solução compatível com a empresa. }\end{array}$ \\
\hline $\begin{array}{l}\text { Contabilidade } \\
\text { Reversa }\end{array}$ & Não utiliza essa prática. \\
\hline Mark-up Reverso & $\begin{array}{l}\text { É feito através da área comercial, que busca o preço dos produtos através de um } \\
\text { shopping e faz o caminho inverso com base no preço de venda. }\end{array}$ \\
\hline $\begin{array}{l}\text { Sistema de } \\
\text { Informações }\end{array}$ & $\begin{array}{l}\text { As informações sobre os concorrentes são mantidas em arquivos digitais. O comercial } \\
\text { elege um segmento, compra-se tudo que tem no mercado, a engenharia avalia custo e } \\
\text { desempenho (engenharia reversa); após isso é feito uma apresentação para a diretoria. Os } \\
\text { relatórios com os pontos fortes e fracos são arquivados num sistema de informações. }\end{array}$ \\
\hline GIC & $\begin{array}{l}\text { Quando indagado sobre a GIC o respondente mencionou desconhecer o assunto; depois } \\
\text { de esclarecido o conceito informou que a empresa não faz uso dessa prática. }\end{array}$ \\
\hline Cadeia de Valor & Não utiliza essa prática. \\
\hline OBA & $\begin{array}{l}\text { O respondente desconhecia o termo. Depois de explicado o conceito disse que não era } \\
\text { uma prática adotada pela empresa. }\end{array}$ \\
\hline
\end{tabular}

Quadro 7 - Práticas de análise externa de custos adotadas pela empresa Chile

Fonte: Dados da pesquisa.

Observa-se que a empresa utiliza com bastante propriedade a engenharia reversa, mantendo sempre atualizado o sistema de informações dos concorrentes. No entanto, as outras práticas não são usuais. Observa-se ainda a utilização da prática do markup reverso, igualmente focado nos concorrentes. Evidencia-se a preocupação da empresa em acompanhar a concorrência, não empregando esforços nas parcerias com clientes e fornecedores.

De acordo com o respondente, a empresa não possui interesse em intensificar o uso dessas práticas, pois, considera que a atual (engenharia reversa) tem atendido suas necessidades decisoriais.

\subsubsection{Empresa Dinamarca}

A empresa atua na produção de implementos agrícolas e componentes automotivos há aproximadamente 45 anos. O Quadro 8 apresenta as informações coletadas na empresa a respeito das práticas abordadas nesse estudo.

\begin{tabular}{|c|l|}
\hline Práticas & \multicolumn{1}{c|}{ Identificação da adoção da prática pela empresa } \\
\hline $\begin{array}{c}\text { Benchmarking } \\
\text { Engenharia } \\
\text { Reversa }\end{array}$ & Não utiliza essa prática. \\
\hline $\begin{array}{c}\text { Contabilidade } \\
\text { Reversa }\end{array}$ & Não utiliziza essa prática, em função de espaço físico, custo capital humano disponível. \\
\hline Mark-up Reverso & Não utiliza essa prática. \\
\hline $\begin{array}{c}\text { Sistema de } \\
\text { Informações }\end{array}$ & Não utiliza essa prática. \\
\hline GIC & $\begin{array}{l}\text { Quando indagado sobre conhecimento da GIC o respondente mencionou não conhecer; } \\
\text { depois de esclarecido o conceito ele informou que a empresa não faz uso dessa prática. }\end{array}$ \\
\hline Cadeia de Valor & $\begin{array}{l}\text { A empresa revisa o processo de alguns fornecedores de serviços e mão-de-obra no no } \\
\text { sentido de racionalizar custos. Em alguns casos já financiou equipamentos, para que o } \\
\text { fornecedor tivesse capacidade de fornecer com a qualidade e requisitos exigidos pela } \\
\text { empresa. Quanto aos clientes, alguns exigem abertura de custos quando o produto sofre } \\
\text { reajustes; os itens elencados são as matérias-primas (80\% custo total) e mão-de-obra. }\end{array}$ \\
\hline OBA & $\begin{array}{l}\text { Com os clientes que representam a curva 80-20, ou seja, 20\% dos clientes representam } \\
80 \% \text { do faturamento, há troca de informações mais detalhadas em função da parceria. }\end{array}$ \\
\hline
\end{tabular}

Quadro 8 - Práticas de análise externa de custos adotadas pela empresa Dinamarca

Fonte: Dados da pesquisa. 
De acordo com o respondente, quando questionado sobre o uso da prática da análise externa de custos, ele afirmou que a empresa ainda caminha para esse objetivo. Atualmente a empresa não está preparada para desenvolver essa prática, por questões de tecnologia e mãode-obra qualificada.

Quanto às informações sobre os concorrentes, a empresa busca as demonstrações contábeis publicadas, porém, segundo o respondente, essa análise não tem influência direta no custo do produto, da produção, ou direcionamento de planos de ação.

Verifica-se pelas informações coletadas com o gerente de planejamento econômico da empresa que o uso das práticas de análise externa de custos é ainda incipiente. Há eventuais relacionamentos com fornecedores e pontuais trocas de informações com clientes.

Diante das informações recebidas é possível identificar que também na empresa Dinamarca há falta de recursos humanos para alavancar o uso das práticas pesquisadas.

\subsubsection{Empresa Espanha}

A empresa Espanha é 100\% brasileira e as sete unidades que possui estão distribuídas entre os estados de Santa Catarina, São Paulo, Pernambuco e Rio Grande do Sul. Possui ainda uma oitava unidade de reflorestamento para atender a necessidade da empresa em termos de embalagens. Quanto à participação de mercado situa-se em $20 \%$, no segmento de motores e $35 \%$ no segmento de fundidos. O Quadro 9 apresenta as principais práticas de análise externa de custos adotadas pela empresa.

\begin{tabular}{|c|l|}
\hline Práticas & \multicolumn{1}{c|}{ Identificação de adoção da prática pela empresa } \\
\hline Benchmarking & Não utiliza esta prática. \\
\hline $\begin{array}{c}\text { Engenharia } \\
\text { Reversa }\end{array}$ & $\begin{array}{l}\text { Não utiliza esta prática. O que se utiliza é a aquisição do produto do concorrente para } \\
\text { testar funcionalidade, durabilidade e qualidade. }\end{array}$ \\
\hline $\begin{array}{c}\text { Contabilidade } \\
\text { Reversa }\end{array}$ & $\begin{array}{l}\text { A empresa analisa as demonstrações contábeis do seu principal concorrente, porém o } \\
\text { respondente relata que essa análise não proporciona as informações de que a empresa } \\
\text { necessita visto tratar de demonstrações - consolidadas, contemplando várias unidades de } \\
\text { negócio da concorrência. }\end{array}$ \\
\hline Mark-up Reverso & $\begin{array}{l}\text { Através do preço do concorrente (fornecido pelos clientes), a empresa tenta custear } \\
\text { matéria-prima e estima mão-de-obra com base em um histórico de participação } \\
\text { percentual desses dois itens sobre o custo total do produto. }\end{array}$ \\
\hline Sistema de & $\begin{array}{l}\text { Dados sobre concorrentes são coletados pela área comercial através dos próprios clientes } \\
\text { da empresa. Não contemplam dados relacionados a custos. }\end{array}$ \\
\hline GIC & $\begin{array}{l}\text { A maior parte dos produtos fabricados pela empresa é considerada especial, ou seja, a } \\
\text { empresa opta por diferenciação e características de aplicabilidade específicas do cliente. } \\
\text { Segundo o entrevistado isso limita muito a aplicação da GIC. }\end{array}$ \\
\hline Cadeia de Valor & $\begin{array}{l}\text { Existem parcerias somente com alguns fornecedores no sentido de racionalizar custos } \\
\text { via aquisição de materiais e equipamentos necessários ao desenvolvimento de novos } \\
\text { itens. Disponibiliza um programa de treinamento aos fornecedores, com o intuito de } \\
\text { evitar retrabalho e perdas. }\end{array}$ \\
\hline OBA & $\begin{array}{l}\text { A abertura de custos ao cliente se dá pelas principais matérias-primas que compõem o } \\
\text { produto; os demais custos são identificados como outros. Essa prática é utilizada } \\
\text { somente quando há reclamação por parte do cliente em função de preço ou reajustes. }\end{array}$ \\
\hline
\end{tabular}

Quadro 9 - Práticas de análise externa de custos adotadas pela empresa Espanha

Fonte: Dados da pesquisa.

O conteúdo do Quadro 9 revela que a empresa utiliza algumas práticas de análise externa de custos e que isso ocorre de forma eventual, não sistematizada. São usadas em casos pontuais quando se tem a real necessidade de analisar participação de mercado, por exemplo, através do preço do concorrente.

As análises das demonstrações contábeis (contabilidade reversa), como outro exemplo, são realizadas pelo entrevistado, porém não tem utilidade com foco estratégico e sim operacional. 
$\mathrm{Na}$ entrevista não foi verificado o interesse da empresa em expandir o uso das práticas pesquisadas. De acordo com o respondente, Coordenador de Custos e Planejamento Estratégico da empresa, o sistema atual tem atendido as necessidades da gestão e, portanto, não há interesse ou planos em alocar mais recursos para ampliar essas atividades. Nota-se, assim, que o nível de adesão ao uso das práticas de gestão externa de custos está muito distante da ênfase apresentada pela literatura.

\subsubsection{Empresa França}

A empresa França é 100\% subsidiária de uma empresa francesa de capital aberto no mercado mundial; têm unidades produtivas no Paraná, São Paulo, Manaus e Rio Grande do Sul; nove filiais de vendas, alguns show-rooms distribuídos pelo território brasileiro e cinco centros de distribuição também localizados no Brasil. A empresa é detentora de sete marcas no segmento que atua. A participação de mercado é pesquisada por produto ou segmento. No geral a empresa participa com $11 \%$ do mercado brasileiro e exporta para mais de 20 países.

\begin{tabular}{|c|l|}
\hline Práticas & \multicolumn{1}{c|}{ Identificação de adoção da prática pela empresa } \\
\hline $\begin{array}{c}\text { Benchmarking } \\
\text { Reversa }\end{array}$ & $\begin{array}{l}\text { Não utiliza esta prática. } \\
\text { de engenharia e compras para estimativa do custo. }\end{array}$ \\
\hline $\begin{array}{c}\text { Contabilidade } \\
\text { Reversa }\end{array}$ & Não utiliza está prática. \\
\hline Mark-up Reverso & Não utiliza esta prática. \\
\hline $\begin{array}{c}\text { Sistema de } \\
\text { Informações }\end{array}$ & $\begin{array}{l}\text { O levantamento de informações da concorrência é feito principalmente por meio de } \\
\text { clientes e de um agente comercial que a empresa mantém somente com a função de } \\
\text { pesquisar o comportamento do concorrente (produto, preço, componentes, entre outros). } \\
\text { A empresa participa de associações específicas do seu ramo de negócio e semestralmente } \\
\text { compra pesquisas com dados do setor de atuação que está inserida. }\end{array}$ \\
\hline GIC & $\begin{array}{l}\text { Por solicitação de redução de custos pelos clientes, a empresa lançou uma linha de } \\
\text { produtos mais barata. Enfatiza que a marioria de seus clientes adquire seus produtos pela } \\
\text { confiabilidade, qualidade, força da marca e tradição. O Uso da GIC é apenas esporádico. }\end{array}$ \\
\hline Cadeia de Valor & $\begin{array}{l}\text { A empresa revela que poderia ser mais atuante na redução de custos principalmente com } \\
\text { fornecedores. Hoje eles não interferem em processos produtivos dos fornecedores. A } \\
\text { cadeia de valor é analisada somente em questões pontuais. }\end{array}$ \\
\hline OBA & $\begin{array}{l}\text { Existe troca de informações quanto aos custos com os fornecedores, porém isso se dá } \\
\text { pontualmente. Com os clientes não existe abertura de dados de custos e isso se justifica } \\
\text { em função de os maiores volumes de faturamento se darem no varejo. Assim, a empresa } \\
\text { considera "perigosa" a abertura dessas informações. }\end{array}$ \\
\hline
\end{tabular}

Quadro 10 - Práticas de análise externa de custos adotadas pela empresa França

Fonte: Dados da pesquisa.

Pela análise dos dados coletados verifica-se que as práticas mais utilizadas pela empresa têm um foco muito mais comercial do que propriamente em gestão estratégica de custos. A empresa está constantemente pesquisando mercado e comportamento do cliente, porém não se verifica uma atuação mais forte da contabilidade gerencial no desenvolvimento das atividades que englobam as práticas de análise externa de custos.

Com base nas informações do entrevistado, coordenador de custos e planejamento estratégico da empresa, nota-se que apesar da apenas pontual utilização de práticas específicas sobre a gestão externa de custos (GIC, cadeia de valor e OBA) e mais sistemática da engenharia reversa, a França é a única das empresas pesquisadas que mantém um profissional totalmente ocupado com a função de pesquisar os desenvolvimentos dos concorrentes. Apesar disso, foi informado pelo respondente que não há, de parte da empresa, planos de utilização mais intensiva das práticas de gestão pesquisadas. 


\subsubsection{Empresa Holanda}

A Holanda é uma empresa multinacional, subsidiária integral de uma empresa holandesa. Em nível mundial atua há mais de 35 anos. Possui uma unidade produtiva no Rio Grande do Sul e parcerias com distribuidores autorizados e presentes em toda a América Latina. No mundo a empresa conta com quatro unidades produtivas, incluindo a brasileira, 35 escritórios de negócios e 1.600 funcionários. No Brasil a participação de mercado no segmento de cilindros hidráulicos é estimada em $75 \%$, sendo de apenas $5 \%$ no de guindastes, este por ainda serem entrantes.

\begin{tabular}{|c|c|}
\hline Práticas & Identificação de adoção da prática pela empresa \\
\hline Benchmarking & Não utiliza essa prática \\
\hline $\begin{array}{c}\text { Engenharia } \\
\text { Reversa }\end{array}$ & $\begin{array}{l}\text { Não existe um levantamento de informações sobre processo de fabricação do } \\
\text { concorrente. A empresa analisa a concorrência com base em suposições do departamento } \\
\text { comercial, de custos e engenharia, com base em experiência anterior. O entrevistado } \\
\text { afirma que é difícil a troca de informações entre os departamentos de compras e a } \\
\text { engenharia, visto não haver engenheiros atuando na unidade do Brasil; todas as } \\
\text { atividades de desenvolvimento de produto são realizadas na Holanda }\end{array}$ \\
\hline $\begin{array}{c}\text { Contabilidade } \\
\text { Reversa }\end{array}$ & Não utiliza essa prática. \\
\hline Mark-up Reverso & Não utiliza essa prática. \\
\hline $\begin{array}{l}\text { Sistema de } \\
\text { Informações }\end{array}$ & $\begin{array}{l}\text { O preço do concorrente normalmente é levantado via clientes. A empresa participa de } \\
\text { uma associação de classe e também do sindicato patronal da categoria, porém, não } \\
\text { existem dados disponíveis nessas entidades que sejam determinantes estrategicamente. } \\
\text { Existe troca de informações através de funcionários que vieram da concorrência ou então } \\
\text { em feiras que a empresa participa. A natureza desses dados é considerada bastante } \\
\text { específica, de acordo com a especialidade da pessoa que estiver tratando de uma questão } \\
\text { pontual. }\end{array}$ \\
\hline GIC & $\begin{array}{l}\text { A empresa aposta em qualidade e funcionalidade do seu produto, variáveis das quais } \\
\text { também dependem o sucesso da GIC. O respondente salienta que o foco da empresa não } \\
\text { é apenas custo, mas valorização de itens como segurança, por exemplo. O uso da GIC é } \\
\text { bastante limitado. }\end{array}$ \\
\hline Cadeia de Valor & $\begin{array}{l}\text { A empresa participa de projetos junto ao fornecedor na compra de matrizes ou melhorias } \\
\text { de processos, na indicação de fornecedores para o fornecedor com o objetivo de } \\
\text { racionalizar custos. Quanto aos clientes não foi mencionada parceria. }\end{array}$ \\
\hline OBA & $\begin{array}{l}\text { A empresa não utiliza o open-book accounting com clientes, embora já tenha sido } \\
\text { solicitado. Essa troca de informações é realizada apenas entre coligadas e controladas do } \\
\text { grupo (Brasil e Exterior). Quanto a fornecedores somente, em casos pontuais a empresa } \\
\text { solicita a abertura, mas é uma prática pouco usada. }\end{array}$ \\
\hline
\end{tabular}

Quadro 11 - Práticas de análise externa de custos adotadas pela empresa Holanda

Fonte: Dados da pesquisa.

O respondente, coordenador de custos da empresa, relata que a maior parte das diretrizes em termos de custos se origina na matriz localizada na Holanda, e que a unidade brasileira não tem muita autonomia neste campo. Isso fica explícito quando informado que todas as atividades de engenharia são desenvolvidas na matriz, limitando totalmente o uso da engenharia reversa como prática de gestão de custos dos concorrentes.

Essa situação acaba se refletindo na adoção de outras práticas pesquisadas: GIC, cadeia de valor e OBA. A adoção de um sistema de informações de concorrentes também ocorre de forma bastante genérica, não havendo contribuições relevantes a serem citadas.

Pelo conteúdo das respostas recebidas é possível entender que a adoção dessas práticas de gestão externa de custos não é prioridade na empresa. $O$ respondente acrescentou que não há planos para mudança da situação atual. Ele reconheceu que a estrutura organizacional adotada no grupo, com a centralização e operacionalização de atividades estratégicas na matriz limita muito maiores avanços em relação aos procedimentos atuais. 


\subsubsection{Análise conjunta das empresas}

A fim de possibilitar uma visão global do conjunto das sete empresas, fez-se a reunião de todas as respostas, conforme apresentado no Quadro 12.

Essa visão global permite constatar que as práticas, quando utilizadas, o são ainda muito parcialmente. Assim, todas as empresas afirmam utilizar, ainda que parcialmente, algumas das técnicas oferecidas pelas práticas de análise externa de custos.

Práticas referenciadas na literatura, como o benchmarking e a GIC podem ser interpretadas como totalmente não utilizadas; para cada uma delas apenas uma empresa reconhece que raramente utiliza.

\begin{tabular}{|c|c|c|c|c|c|c|c|}
\hline \multirow{2}{*}{ Práticas } & \multicolumn{7}{|c|}{ Empresas } \\
\cline { 2 - 8 } & Argentina & Brasil & Chile & Dinamarca & Espanha & França & Holanda \\
\hline Benchmarking & Raramente & Não & Não & Não & Não & Não & Não \\
\hline $\begin{array}{c}\text { Engenharia } \\
\text { Reversa }\end{array}$ & Não & Utiliza & Utiliza & Não & Não & Utiliza & Não \\
\hline $\begin{array}{c}\text { Contabilidade } \\
\text { Reversa }\end{array}$ & Raramente & Raramente & Não & Não & Raramente & Não & Não \\
\hline $\begin{array}{c}\text { Mark-Up } \\
\text { Reverso }\end{array}$ & Não & Não & Utiliza & Não & Raramente & Não & Não \\
\hline $\begin{array}{c}\text { Sistema de } \\
\text { Informações }\end{array}$ & Raramente & Raramente & Utiliza & Não & Raramente & Utiliza & Raramente \\
\hline $\begin{array}{c}\text { GIC } \\
\text { Cadeia de } \\
\text { Valor }\end{array}$ & Raramente & Não & Não & Utiliza & Utiliza & Não & Utiliza \\
\hline OBA & Raramente & Não & Não & Utiliza & Utiliza & Raramente & Utiliza \\
\hline
\end{tabular}

Quadro 12 - Uso das práticas de análise externa de custos adotadas pelas empresas pesquisadas Fonte: Dados da pesquisa.

O Quadro 12 evidencia como as empresas se comportam em relação às práticas de análise externa de custos, ou seja, o quanto incorporam em sua gestão o que preceitua a teoria. Verifica-se que o uso da matéria ainda é bastante tímido, não há um conhecimento aprofundado sobre o tema e tampouco perspectivas de sua utilização.

Além das anteriormente referenciadas (benchmarking e GIC) também as práticas de contabilidade reversa, markup reverso não são utilizadas. As demais (cadeia de valor, openbook accounting, e engenharia reversa) são utilizadas por menos da metade delas e não de forma intensiva conforme os benefícios enfatizados pela literatura. Entre as não utilizadas e as utilizadas moderadamente tem-se o sistema de informações, presente em apenas duas empresas.

Todos os respondentes, de alguma forma, salientaram a dificuldade de aplicar a teoria na prática em função de disponibilidade de recursos para implantação (financeiros, pessoas, tempo). Uma das empresas (Holanda) justifica a não utilização devido a concentração de varias atividades na matriz holandesa. A validação da teoria que envolve a análise externa de custos ainda se dá de forma muito parcial, pelo menos na amostra pesquisada. Verifica-se ainda falta de planos para desenvolver ou expandir o uso das práticas pesquisadas, sinalizando que para estas empresas esse quadro não deve se alterar de forma significativa no curto prazo.

\section{CONCLUSÕES}

Este estudo objetivou verificar a adoção das práticas de análise externa de custos por empresas da Serra Gaúcha. Além da representatividade do setor metal-mecânico da região, destaca-se também o perfil das sete empresas pesquisadas (empresas de grande porte, 
significativa representatividade nos mercados de atuação, destacada estrutura de negócio participação integral de capital estrangeiro em duas delas). Com base nesse perfil, e de acordo com o que preceitua a literatura da área, há, em princípio, expectativa de alto grau de adoção.

Entretanto, verifica-se que é tímido o uso das práticas pesquisadas. Muitas delas não são aplicadas sequer parcialmente. Há troca de informações na cadeia, porém ainda com restrições dado o baixo nível de confiança ou transparência entre os participantes. Todos os entrevistados revelaram, que informações sobre custos ainda são fechadas e de difícil acesso.

De acordo com os critérios de cortes definidos como metodologia para análise dos dados, das sete empresas pesquisadas, o Brasil e a Argentina utilizam raramente as práticas externas de custos pesquisadas, o que significa dizer que pelo menos uma das práticas pesquisadas é adotada por duas das empresas da amostra, com relação às demais empresas, ambas utilizam parcialmente as práticas pesquisadas, o que significa afirmar que duas ou mais das práticas são adotadas por essas empresas.

A prática mais identificada nas empresas e também apontada como mais acessível é a engenharia reversa. Parece que desmontar produtos do concorrente e custear os materiais e processos usados na sua composição é uma atividade mais simples, pelo menos na ótica de três das sete empresas. Isso também ocorreu com duas outras práticas, a cadeia de valor e o OBA.

Em função disso, e dado o objetivo deste estudo, conclui-se que há ainda uma distância considerável entre teoria desenvolvida e a prática empresarial. Outra observação pertinente, e complementar ao objetivo do estudo, é quanto ao desconhecimento dos termos técnicos que envolvem a análise externa de custos (análise dos custos dos concorrentes, GIC, open-book accounting, contabilidade reversa, mark-up reverso). Isso chega a ser surpreendente dada a formação superior e experiência dos entrevistados.

Alguns argumentos são apresentados para justificar a não utilização das práticas pesquisadas. A falta de recursos humanos e materiais, não prioridade frente a outras atividades, satisfação com as informações atualmente disponíveis, dificuldades em obter informações externas e concentração de atividades estratégicas na matriz são as mais citadas. De qualquer forma, o uso efetivo das práticas pesquisadas mostra um distanciamento significativo em relação ao conteúdo abordado na literatura sobre a necessidade e utilidade delas para gestão das empresas em mercados competitivos.

Quanto às limitações deste estudo, pode-se apontar a sua validade somente para a realidade das empresas pesquisadas, o que prejudica a generalização dos resultados.

Durante o desenvolvimento do estudo notou-se a ausência de estudos empíricos que objetivem investigar o efetivo uso das práticas tratadas nesta pesquisa. Assim, sugere-se o desenvolvimento de estudos utilizando amostras mais representativas e com aplicação de pesquisas tipo survey. Entende-se que trabalhos mais robustos poderão trazer elementos que validem, rejeitem ou pelos menos ajudem a melhor compreender os resultados de pesquisas como esta aqui apresentada. Investigar em maior amplitude as possíveis causas de não adoção pode, também, contribuir para uma análise crítica da teoria até então desenvolvida.

\section{REFERÊNCIAS}

AGNDAL, H.; NILSSON, U. Interorganizational cost management in the exchange process. Management Accounting Research, v. 20, n.2, p. 85-101, 2008. http://dx.doi.org/10.1016/j.mar.2008.07.001

AGNDAL, H.; NILSSON, U. Different open book accounting practices for different purchasing strategies. Management Accounting Research, n. 21, p.147-166, 2010. http://dx.doi.org/10.1016/j.mar.2010.04.001

AGUIAR, A. B.; REZENDE, A. J.; ROCHA, W. Uma análise da complementaridade entre 
gestão interorganizacional de custos e open-book accouting. BASE. Revista de Administração e Contabilidade da Unisinos, v. 5, n. 1, p. 66-76, 2008.

BACIC, M. J. Escopo da gestão estratégica de custos em face das nações de competitividade e de estratégia empresarial. In: CONGRESSO BRASILEIRO DE GESTÃO ESTRATÉGICA DE CUSTOS, 1, 1994, São Leopoldo. Anais... São Leopoldo: ABCustos, 1994.

BANCO NACIONAL DE DESENVOLVIMENTO ECONÔMICO E SOCIAL (BNDES). Carta Circular No 10/2010, Normas relativas ao porte das beneficiárias. São Paulo, 2010.

BARTZ, D.; STAUDT, T.; SOUZA, M. A. Gestão estratégica de custos: uso da engenharia reversa na análise dos custos dos concorrentes. BASE. Revista de Administração e Contabilidade da Unisinos, v. 2, n. 3, p. 167-175, 2005.

BORINELLI, M. L.; ROCHA, W. Análise estratégica de cadeia de valor: um estudo exploratório do segmento indústria - varejo. Revista Contemporânea de Contabilidade, v. 1, n. 7, p. 145-165, jan./jun. 2007.

CASELLA, B. M. B. X. Análise de custos de concorrentes: estudo exploratório no setor de celulose e papel. Dissertação (Mestrado em Ciências Contábeis) - Universidade de São Paulo, São Paulo, 2008.

CINQUINI, L.; TENUCCI, A. Strategic management accounting: exploring distinctive features and links with strategy. MPRA Paper, n. 212, nov. 2007. Disponível em: <http://mpra.ub.uni.muenchen.de/212/>. Acesso em: 30 set. 2010.

COASE, R. The institutional structure of production. American Economic Review, n. 82, p. 713-719, 1991.

COKINS, G. Measuring costs across the supply chain. Cost Engineering, v. 43, n. 10, p. 25 $31,2001$.

COOPER, R.; SLAGMULDER, R. Extra-organizational cost analysis. Management Accouting, v. 80, n. 1, p. 14-15, 1998.

COOPER, R.; SLAGMULDER, R. Supply chain development for the lean enterprise: interorganizational cost management. New Jersey: The IMA Foundation for Applied Research, Inc. 1999.

COOPER, R.; SLAGMULDER, R. Interorganizational costing, part 1. Cost Management, v. 17, n. 5, p.15-22, 2003.

COOPER, R.; SLAGMULDER, R. Cost analysis outside the organization. Cost Management, v. 18, n. 3, p. 44-46, 2004.

DESCHAMPS, J.-P.; NAYAK, P. R. Product juggernauts: how companies mobilize to generate a stream of market winners. Boston: HBSP, 1995.

FLORES, J. S.; SILVEIRA, M. S.; SOUZA, M. A.; SANTOS, M. V. Fatores condicionantes para implementação da gestão interorganizacional de custos: um estudo empírico em empresas do Rio Grande do Sul. In: CONGRESO DE COSTOS DEL MERCOSUL, 5., 2010, La Plata. Anais... La Plata: IAPUCO, 2010.

GIL, A. C. Métodos e técnicas de pesquisa social. 5. ed. São Paulo: Atlas. 1999.

GUILDING, C. Competitor-focused accounting: an exploratory note. Accouting Organization and Society, v. 24, n. 7, p. 583-595, 1999. http://dx.doi.org/10.1016/S03613682(99)00007-0

GORDON, I. H. De olho na concorrência: como vencer a batalha por mercados e clientes. 
São Paulo: Futura, 2004.

HAMEL, F.; PRAHALAD, C. K. Competindo pelo futuro. Rio de Janeiro: Campus, 1995.

HEINEN, K. C.; HOFFJAN, A. The strategic relevance of competitor cost assessment: an empirical study regarding competitor accounting. Journal of Applied Management Accounting Research, v. 3, n. 1, p. 17-34, 2005.

JOHNSON, H. T.; KAPLAN, R. S. Relevance lost. Boston: HBSP, 1987.

KAJUTER, P.; KULMALA, H. L. Open-book accounting in networks: potential achievements and reasons for failures. Management Accounting Research, v. 16, n. 2, p. 179-204, 2005. http://dx.doi.org/10.1016/j.mar.2005.01.003

LAKATOS, E. M.; MARCONI, M. A. Técnicas de pesquisa: planejamento e execução de pesquisas, amostragens e técnicas de pesquisa, elaboração, análise e interpretação de dados. 4. ed. São Paulo: Atlas, 1999.

LEITE, J. Contabilidade de gestão contingencial: uma perspectiva estratégica. In: CONGRESSO DE CONTABILIDADE E AUDITORIA, 8., 2000, Aveiro. Anais... Aveiro, ISCA, 2000.

MACHADO, D. G.; SOUZA, M. A. Análise das relações entre a gestão de custos e a gestão do preço de venda. Revista Universo Contábil, v. 2, n. 1, p. 34-60, jan./abr. 2006.

MARTINS, E. Contabilidade de custos. 9. ed. São Paulo: Atlas, 2003.

MIRANDA, L. C. Gerenciamento de cadeia de valor. In: SCHIMIDT, Paulo (org.). Controladoria: agregando valor para a empresa. Porto Alegre: Bookman, 2002. pp 201-212.

MONDEN, Y. Cost reduction systems: target costing and kaizen costing. New York: Productivity Press, 1995.

MOON, P.; BATES, K. Core analysis in strategic performance appraisal. Management Accounting Research, v. 4, p. 139-152, 1993. http://dx.doi.org/10.1006/mare.1993.1009

MOREIRA, J. M. A ética empresarial no Brasil. São Paulo: Pioneira, 1999.

OLIVA, F. L.; SOBRAL, M. C.; TEIXEIRA, H. J. Sistema do processo de análise das relações interorganizacionais para o desenvolvimento sustentado. In: EnANPAD, 30., 2006, Salvador. Anais... Rio de Janeiro: ANPAD, 2006.

OLIVEIRA, S. L. Tratado de metodologia científica. São Paulo: Atlas, 1998.

QUESADO, P. R.; RODRIGUES, L. L. A gestão estratégica de custos em grandes empresas portuguesas. Revista Iberoamericana de Contabilidad de Gestion, v. 1, n. 10, p. 121-143, 2007.

PEREZ JUNIOR, J. H; OLIVEIRA, L. M.; COSTA, R. G. Gestão estratégica de custos. São Paulo: Atlas, 1999.

PIL, F. K.; HOLWEG, M. Envolving from value chain to value grid. MIT Sloan Management Review, v. 47, n. 4, p. 72-80, 2006.

PORTER, M. E. Vantagem competitiva. 5. ed. Rio de Janeiro: Campus, 1992.

PORTER, M. E. Estratégia competitiva: técnicas para análise de indústrias e da concorrência. 2. ed. Rio de Janeiro: Elsevier, 2004.

ROESCH, S. M. A. Projetos de estágio e de pesquisa em administração. 3 ed. São Paulo: Atlas, 2009. 
SIMMONDS, Kenneth. Strategic management accounting. Management Accounting, p. 2629, april 1981.

SINDICADO DAS INDÚSTRIAS METALURGICAS, MECÂNICAS E DE MATERIAL ELÉTRICO DE CAXIAS DO SUL (SIMECS). Pesquisa de empresa. 2009. Disponível em: <http://www.simecs.com.br>. Acesso em: 23 set. 2010.

SHANK, J. K.; GOVINDARAJAN, V. A revolução dos custos. Rio de Janeiro: Campus, 1997.

SOUZA, B. C. Fatores condicionantes da gestão de custos interorganizacionais. Dissertação (Mestrado em Ciências Contábeis) - Universidade de São Paulo, São Paulo: 2008.

SOUZA, B. C; ROCHA, W. Fatores condicionantes da gestão de custos interorganizacionais. In: CONGRESSO USP DE CONTROLADORIA E CONTABILIDADE, 8., São Paulo, 2008. Anais... São Paulo: FEA/USP, 2008.

SOUZA, B. C.; ROCHA, W. Gestão de custos interorganizacionais. São Paulo: USP, 2009.

WERNKE, R. Gestão de custos: uma abordagem prática. 2. ed. São Paulo: Atlas, 2008.

YIN, R. K. Estudo de caso: planejamento e métodos. Porto Alegre: Bookman. 2005. 